\title{
SABERES DOCENTES E EDUCAÇÃO GEOGRÁFICA: POSSÍVEIS DIÁLOGOS
}

\author{
Teaching knowledge and geographic education: possible dialogues
}

Edimar Eder Batista*

\begin{abstract}
* Doutorando em Geografia pela Universidade Estadual de Londrina (UEL), professor da rede estadual de ensino do Paraná -
\end{abstract} edimarbat@gmail.com

Recebido em 03/08/2018. Aceito para publicação em 20/08/2018.

Versão online publicada em 03/09/2018 (http://seer.ufrgs.br/paraonde)

\begin{abstract}
Resumo:
Com base em pressupostos teóricos acerca dos saberes docentes e da educação geográfica, propõe-se a seguinte questão, a ser contemplada neste estudo num viés teórico: há relações entre os saberes docentes e a efetivação da educação geográfica na educação básica? A interpretação da bibliografia consultada sugere que sim. Objetivando refletir sobre as possibilidades de contribuição dos saberes docentes para o aprimoramento da atuação do professor de Geografia rumo à efetivação de uma educação geográfica, o texto contempla: a associação da noção de saber à ideia de exigência de racionalidade; a profissionalização do ensino à explicitação dos saberes da ação pedagógica; a construção conceitual na educação geográfica; e as interfaces entre saberes docentes, educação geográfica e a noção de relação com o saber.
\end{abstract}

Palavras-chave: saber, educação geográfica, professor.

\begin{abstract}
:
Based on theoretical assumptions about teaching knowledge and geographic education, it is proposed the following question, to be considered in this essay in a theoretical bias: are there relationships between teaching knowledge and the effectiveness of geographic education in the basic education? The interpretation of the consulted bibliography suggests yes. Aiming to reflect about the possibilities of contributions on the teaching knowledge to improve geography teacher's performance, towards the effectiveness of a geographic education, this text contemplates: the association about notion of knowing to the idea of requirement of rationality; the professionalization of teaching to the knowledge explanation of pedagogical action; conceptual construction in the geographic education; and the interfaces between teaching knowledge, geographic education and the notion of relationship with the knowledge.
\end{abstract}

Key-words: knowledge, geographic education, teacher.

\section{Introdução}

Assim como Tardif (2014) e Gauthier et al (1998), compreende-se a prática docente como uma atuação profissional na qual o professor é sujeito ativo da construção do saber e não apenas um ator que transmite saberes produzidos por outros, mas que, no entanto, tais saberes docentes dos profissionais atuantes na escolarização básica, para serem reconhecidos enquanto conhecimento, precisam ser explicitados, analisados e validados pela pesquisa científica.

Corrobora-se também com Callai (2013) quanto à potencialidade da Geografia escolar desenvolver um pensamento espacial criando condições para que os alunos possam construir as ferramentas intelectuais que os permitam compreender a sua espacialidade, ou seja, com a construção de uma educação geográfica, que, para a referida autora, está contida na dimensão pedagógica da ciência geográfica e da Geografia escolar, e atrelada à proposição de incorporar no processo de ensino o desenvolvimento de um pensamento geográfico, constituindo-se na superação de um ensino transmissor de informações para um ensino que pense a realidade em que vivemos, considerando a 
base do pensamento geográfico, os conceitos.

Partindo destes pressupostos teóricos acerca dos saberes docentes e da educação geográfica, propõe-se a seguinte questão, a ser contemplada neste estudo num viés teórico: Há relações entre os saberes docentes e a efetivação da educação geográfica na educação básica?

A bibliografia consultada sugere que sim. Contudo, esta temática das interfaces entre saberes docentes e educação geográfica encontra-se, ainda, pouco explorada nas publicações científicas sobre o ensino de geografia, em nosso país, justificando a pertinência do presente estudo, que objetiva refletir sobre as possibilidades de contribuição dos saberes docentes para o aprimoramento da atuação do professor de Geografia rumo à efetivação de uma educação geográfica.

Para alcançar o objetivo proposto, o texto contempla: 1) a associação, de maneira global, mas sistemática, da noção de saber à ideia de exigência de racionalidade, segundo a qual o saber deve ser justificado por razões e motivos que o validem para o discurso ou para a ação, atrelada a ideia de que a profissionalização do ensino está intimamente ligada à explicitação dos saberes da ação pedagógica. 2) a concepção de que a educação geográfica objetiva a construção dos conceitos específicos da Geografia enquanto instrumentos para a compreensão da espacialidade e, por fim, 4) as interfaces entre saberes docentes, educação geográfica e a noção de relação com o saber, de Charlot $(2000,2013)$.

0 texto estrutura-se em três itens, conforme temas descritos no parágrafo anterior, além das considerações finais.

\section{Explicitação dos saberes docentes}

As pesquisas relacionadas aos saberes docentes, iniciadas nas duas últimas décadas do século passado, alinham-se com o contexto concreto da atuação do professor. Tal referencial teórico pode possibilitar a compreensão do trabalho do professor real, e não do professor ideal. Mas o que são os saberes docentes ou o saber docente?

Ao questionar se os profissionais do ensino desenvolvem e/ou produzem realmente "saberes" oriundos de sua prática, Tardif (2014) toca no ponto nevrálgico da problemática em questão. As pesquisas recentes acerca desta temática apontam que a resposta é sim.

O ensino é caracterizado por Gauthier et al (1998) como um ofício sem saberes e como saberes sem ofício, no primeiro há um ofício sem saberes pedagógicos específicos e, no segundo, há uma redução do ofício a saberes que provocam o esvaziamento do contexto concreto do exercício do ensino, resultando no retardamento da eclosão de pesquisas específicas sobre o ensino.

Um ofício sem saberes e saberes sem ofício são dois erros aos quais Gauthier et al $(1998$, p. 28) contrapõe uma concepção segundo a qual, no ensino, vários saberes são mobilizados pelo professor, formando uma "espécie de reservatório no qual o professor se abastece para responder a exigências específicas de uma situação concreta de ensino".

Concebe-se que o ensino não constitui nem um ofício sem saberes, nem saberes sem ofício, mas sim um ofício ou trabalho que possui saberes específicos que prescindem de investigações que o explicitem a fim de que esta atividade alcance o status de profissão. Neste sentido, corrobora-se com as ideias de Gauthier et al (1998) e de Tardif (2014) expressas a seguir.

Duas teses são propostas por Tardif (2014) em relação aos saberes docentes:

- a de que os professores são sujeitos do conhecimento e possuem saberes específicos ao seu ofício; e

- a de que a prática, o trabalho cotidiano dos professores não é somente um lugar de aplicação de saberes produzidos por outros, mas também um espaço de produção, transformação e mobilização de saberes que lhe são próprios.

Para Gauthier et al (1998) a pesquisa de um repertório de conhecimentos específicos do ensino se efetua a partir de dois postulados fundamentais:

- existe um repertório de conhecimentos peculiar à função de professor que distingue essa ocupação das outras profissões e do saber do cidadão comum;

- a determinação desse repertório de conhecimentos se dá pelo estudo do trabalho docente.

As concepções destes autores contribuem para a compreensão da prática docente como uma atuação profissional na qual o professor é sujeito ativo da construção do seu saber e não apenas um 
ator que transmite saberes produzidos por outros.

A aceitação destas concepções implica a retomada da definição do que são os saberes docentes ou o saber docente? Definição não, melhor falar em delimitação, em virtude da complexidade da questão.

Em razão da impossibilidade de progresso nas pesquisas relacionadas ao tema sem a produção de noção precisa e operatória de saber para suportar as investigações empíricas, Tardif (2014) propõe uma refocalização conceitual global da noção de saber, reconhecendo, no entanto, que:

Na verdade, ninguém é capaz de produzir uma definição de saber que satisfaça todo mundo, pois ninguém sabe cientificamente, nem com toda a certeza, o que é um saber. Devemos então, contentar-nos com uma definição de uso restrito, decorrente de certas escolhas e de certos interesses, principalmente daqueles ligados à nossa pesquisa. 0 importante aqui é estarmos conscientes dessas escolhas e desses interesses e compreendermos seu caráter relativo, discutível e, por conseguinte, revisável (TARDIF, 2014, p. 193).

Conforme Tardif (2014), no âmbito da modernidade, o saber foi definido de três maneiras, em função de três lugares ou topos: a subjetividade, o julgamento e a argumentação, sendo a terceira, a concepção com a qual o autor coaduna, por considerar que ele se desenvolve no espaço do outro e para o outro, possuindo uma dimensão intersubjetiva.

Segundo esta concepção, o saber não se reduz a uma dimensão subjetiva, nem a asserções teóricas de base empírica, ele implica sempre o outro, isto é, uma dimensão social fundamental, na medida em que o saber é justamente uma construção coletiva, de natureza linguística, oriunda de discussões, de trocas discursivas entre seres sociais (TARDIF, 2014, p. 196-197).

Gauthier et al (1998, p. 339) definem o saber sob os ângulos discursivo, argumentativo e comunicacional:

Em última análise, consideramos o saber dos professores sob o ângulo argumentativo e social. De fato, propomo-nos a encarar o saber como a expressão de uma razão prática. E essa razão prática depende muito mais da argumentação e do juízo do que da cognição e da informação.

O saber dos professores pode ser pesquisado, portanto, tendo por foco seu caráter interativo, comunicacional nos contextos de trabalho docente. Contudo, a aceitação desta premissa não exime o pesquisador da objetividade intrínseca ao trabalho científico. A articulação desta objetividade com o caráter argumentativo e comunicacional do saber é possível, para Gauthier et al (1998) e Tardif (2014) por meio da exigência de racionalidade.

Embora proponham que a noção de saber seja associada, de maneira global, mas sistemática, a essa ideia de exigência de racionalidade, Tardif (2014) e Gauthier et al (1998), compreendem esta racionalidade não como definida a priori por preceitos e modelos demasiados rígidos da pesquisa científica, mas através da comunicação entre agentes e de sua capacidade de argumentar, não resultando, pois, de uma razão que está além da linguagem e da práxis. "Portanto, as exigências de racionalidade dependem do contexto de interação e das razões alegadas pelos sujeitos" (GAUTHIER et al, 1998, p. 339).

Na elaboração racional que justifica a prática é que reside, a distinção entre saber e um discurso vazio da racionalidade.

Acreditamos que essa ideia de "exigência de racionalidade" fornece uma pista muito interessante para as pesquisas sobre os saberes dos professores, pois ela permite restringir nosso campo de estudo aos discursos e ações cujos locutores, os atores, são capazes de apresentar uma ordem qualquer de razão para justifica-los. (TARDIF, 2014, p. 198-199).

Os saberes docentes existem. São racionais, mas não necessariamente científicos, são sociais e não 
idiossincráticos, e, por isso, não são inquestionáveis. É um saber construído primordialmente na ação de trabalho cotidiana, objetivando não a produção de conhecimentos teóricos, mas fins práticos.

Neste sentido, corrobora-se com as constatações de Tardif $(2014$, p. 224) de que os saberes docentes apoiam-se em uma racionalidade concebida em função da realidade dos atores sociais empenhados em atividades contingentes, portanto, numa "[...] racionalidade limitada e concreta, enraizada nas práticas cotidianas dos atores, racionalidade aberta, contingente, instável, alimentada por saberes lacunares, humanos, baseados na vivência, na experiência, na vida".

A explicitação dos saberes docentes, por meio das pesquisas científicas sobre o ensino, atendendo às exigências de racionalidade pode contribuir para a profissionalização dos professores.

Para tanto, há que se considerar duas premissas. 0 saber docente é um saber social (TARDIF, 2014). A racionalidade do saber docente é distinta da racionalidade técnica ou teórica da academia (GAUTHIER et al, (1998), (LOPES, 2010), (TARDIF, 2014). Premissas presentes no conceito de saberes da ação pedagógica.

Os saberes da ação pedagógica, conceito criado por Gauthier et al (1998), representam um repertório de conhecimentos sobre o ensino. Sua identificação e consolidação dependem da realização de pesquisas científicas que tornem públicas as formas de pensar e agir dos professores no exercício de seu trabalho. Na ausência de um saber da ação pedagógica válido, segundo este autor, o professor continuará recorrendo à experiência, à tradição, ao bom senso, ou seja, continuara usando saberes que além de poder comportar limitações importantes também não o distinguem em nada, ou em quase nada, do cidadão comum

Como o saber docente é social, o ensino numa sala de aula, assim como pode ser considerado uma atividade singular, mergulhada em fenômenos de contingência, com dificuldades de generalização, também pode ser visto como uma atividade que possui uma estrutura suficientemente estável para ser estudada, cujas dimensões são relativamente recorrentes. Ou seja, sua estabilidade não impede que ele comporte também sua singularidade (GAUTHIER et al 1998).

0 estabelecimento de um repertório de saberes docentes, para estes autores, requer que se avance das contingências à generalidade. Os professores possuem um saber experiencial, singular, que embasa julgamentos dos mesmos acerca do exercício de sua atividade, contudo, é preciso explicitar tais julgamentos e os motivos que os fundamentam para que o ensino não se reduza à compilação de práticas pedagógicas e para que este saber experiencial, submetido a uma validação científica, constitua um repertório de conhecimentos do ensino, o saber da ação pedagógica (GAUTHIER et al, 1998).

O que é, precisamente, o saber da ação pedagógica. "O saber da ação pedagógica é o saber experiencial dos professores a partir do momento em que se torna público e que é testado através das pesquisas realizadas em sala de aula" (GAUTHIER et al, 1998, p. 33).

Neste sentido, a profissionalização do ensino está intimamente ligada à explicitação dos saberes da ação pedagógica, que constituem um dos fundamentos da identidade profissional dos professores (GAUTHIER et al, 1998).

\section{Educação geográfica e conceitos}

A Geografia, enquanto ciência possui um arcabouço conceitual próprio e conceitos compartilhados com outras ciências. Quando organizados objetivando o ensino-aprendizagem na educação básica, os conhecimentos científicos desta área do saber compõe a Geografia escolar.

A Geografia escolar deve desenvolver um pensamento espacial, para tanto, o ensino de Geografia deve resultar na oferta de condições para que os alunos possam construir as ferramentas intelectuais que os permitam compreender a sua espacialidade (CALLAI, 2013).

Esta autora define o conceito de educação geográfica, atrelado à proposição de incorporar no processo de ensino o desenvolvimento de um pensamento geográfico, constituindo-se na superação de um ensino transmissor de informações para um ensino que pense a realidade em que vivemos, considerando a base do pensamento geográfico, os conceitos.

A educação geográfica esta contida, pois, na dimensão pedagógica da ciência geográfica e da 
Geografia escolar.

O entrelaçamento do discurso da ciência, do discurso da geografia escolar e a dimensão pedagógica que está neles embutido permite o encaminhamento da educação geográfica. A tarefa de fazer a educação geográfica supõe desenvolver o pensamento espacial e trabalhar com os conceitos de modo que eles sejam significativos para desencadear as aprendizagens (CALLAI, 2013, p. 18).

Depreende-se das concepções de Callai (2013) que a educação geográfica objetiva a construção dos conceitos específicos da Geografia enquanto instrumentos para a compreensão da espacialidade.

A Educação Geográfica caracteriza-se, então, pela intenção de tornar significativos os conteúdos para a compreensão da espacialidade, e isso pode acontecer por meio da análise geográfica, que exige o desenvolvimento de raciocínios espaciais (CALLAI, 2013, p. 44 grifo nosso).

Racionar espacialmente requer o domínio, ou, pelo menos o reconhecimento de uma rede de conceitos geográficos e de áreas afins. A relevância dos conceitos no ensino de Geografia é apontada, dentre outros autores, por (CAVALCANTI, 1998; 2012), (COUTO, 2005) e (KIMURA, 2008). No âmbito de uma educação geográfica, os conceitos são, portanto, instrumentos cognitivos que possibilitam àqueles que os utilizam, a compreensão abstrata das materialidades espaciais.

\section{Saberes docentes, educação geográfica e relação com o saber: possíveis diálogos}

Como os saberes docentes podem articular-se com a educação geográfica? Sem pretender esgotar a questão, pelo contrário, procurando apenas tecer algumas considerações iniciais acerca do tema, apontam-se as concepções de relação com o saber, de Charlot (2000; 2013), como possível elo entre ambas.

Para Charlot (2000) o saber não existe em si, o saber é uma relação, portanto, há que se compreender a relação com o saber.

Neste sentido, conforme este autor é incorreto conceber que um sujeito tem uma relação com o saber, visto que o sujeito é a relação com o saber, em outras palavras, a ideia de saber implica a de sujeito, de atividade do sujeito, de relação do sujeito com ele mesmo, de relação desse sujeito com os outros, que constroem conjuntamente, controlam, validam, partilham esse saber.

A proposição básica de Charlot (2000) é de que a relação com o saber é uma forma de relação com o mundo, enquanto conjunto de significados, mas, também, como espaço de atividades que se inscreve no tempo.

Embora afirme que "Toda relação com o saber, enquanto relação de um sujeito com seu mundo, é relação com o mundo e com uma forma de apropriação do mundo: toda relação com o saber apresenta uma dimensão epistêmica" (CHARLOT, 2000, p. 72) constata também que esta relação comporta uma dimensão de identidade, que, entretanto, mesmo sendo de um sujeito, não deixa se ser uma relação social.

Depreende-se das ideias de Charlot $(2000,2013)$ que aprender, ou seja, entrar numa relação com o saber, relação com o mundo, relação consigo mesmo, relação com os outros, precisa contemplar a relação simbólica intrínseca a este processo. Relação simbólica na qual a distinção entre os saberes enquanto práticos ou teóricos perde o sentido.

[...] o saber não existe senão sob formas específicas. 0 erro, no entanto, consiste em acreditar-se que essas são formas específicas de um objeto natural que se chamaria "saber", do qual poder-se-iam definir espécies e variedades, quando, na verdade, são formas específicas de relação com o mundo. [...] Assim, que é que, em um saber, possibilita considera-lo prático? Não é o próprio saber que é prático, mas, sim, o uso que é feito dele, em uma relação prática com o mundo. Essa distinção permite evitar falsos debates (CHARLOT, 2000, p. 62). 
Se o saber é relação, não existe saberes práticos ou teóricos, mas relação com o saber de caráter mais prático ou mais teórico.

A concepção do saber enquanto relação, de Charlot (2000), possui desdobramentos educacionais. Primeiro, a impossibilidade de autonomizar o produto do aprendizado, separando-o da relação. Segundo, o aprender é a capacidade de regular a relação consigo próprio, a relação com os outros, a relação consigo próprio através da relação com os outros e reciprocamente.

Se, a educação geográfica vislumbra que a apropriação conceitual permita ao estudante a autonomia intelectual inscrita na realização de analises geográficas a partir de um raciocínio espacial, ela prescinde de um professor que conceba suas práticas de ensino e aprendizagem com seus alunos com base em um saber seu, próprio. Ou seja, a autonomia intelectual do aluno requer a autonomia do saber do professor.

A efetivação de uma educação geográfica é bastante prejudicada sem um professor que possua uma postura ativa, criativa, reflexiva e crítica em relação ao saber do qual se apropriou ao longo de sua formação e atuação profissional. Noutras palavras, a educação geografia é praticamente impossibilitada sem o domínio dos saberes docentes por parte do professor, mesmo que este domínio aconteça inconsciente, ou seja, sem a consciência teórica da teoria dos saberes docentes.

O saber, concebido enquanto relação interacional (TARDIF; LESSARD, 2013), reafirma a postura ativa do professor e do aluno no processo de ensino e aprendizagem, conferindo responsabilidades específicas a ambos. Ao professor cabe gerir pedagogicamente sua atuação com vistas a estimular reflexões espaciais dos estudantes, o que é aprimorado com o tempo de atuação em sala de aula, se as experiências temporalmente advindas forem apropriadas pelo docente enquanto saberes. Ao aluno cabe engajar-se ativamente em seu aprendizado, a partir das explicitações de seu professor em relação ao saber, ao conhecimento, apresentado enquanto fruto das relação deste estudante consigo mesmo, com os outros e com o mundo social no qual está inserido.

\section{5. (In)conclusões}

Há relações entre os saberes docentes e a efetivação da educação geográfica na educação básica? Sim. Estes saberes podem contribuir para tanto, a partir da possibilidade de aprimoramento da atuação profissional do professor de Geografia.

0 professor apropria-se de saberes durante sua atuação profissional que, conciliados com os saberes adquiridos ao longo de sua vida e de sua formação inicial e contínua, constituem um repertório de conhecimentos passíveis de serem validados pelas pesquisas no campo do ensino enquanto saberes sociais profissionais dotados de racionalidade e generalidade.

A educação geográfica necessita de um professor consciente de seus saberes para empregá-los de maneira pensada e planejada no ensino com vistas ao desenvolvimento de formas de pensar espaciais por parte de seus alunos, conferindo-lhes autonomia intelectual.

A concepção de saber como relação com o saber, envolvendo as interações humanas que oportunizam o acesso ao conhecimento socialmente construído pelo homem enquanto ser social une as possibilidades de diálogo entre os saberes docentes e a educação geográfica.

Estas considerações, por serem teóricas, são inconclusivas. Vislumbram-se possibilidades de enriquecimento mútuo a partir da interação entre as três concepções abordadas, os saberes docentes, a educação geográfica e a relação com o saber. No entanto, somente a realização de pesquisas em âmbito prático, da atuação docente na escolarização básica podem confirmar as potencialidades esboçadas. Que elas se realizem!

\section{Referências}

CALLAI, Helena C. A formação do profissional de Geografia: o professor. Ijuí: Editora Unijuí, 2013. 
CAVALCANTI, Lana de S. Geografia, escola e construção de conhecimentos. Campinas: Papirus, 1998.

0 ensino de geografia na escola. Campinas: Papirus, 2012.

CHARLOT, Bernard. Da relação com o saber: elementos para uma teoria. Trad. Bruno Magne. Porto Alegre: Artmed, 2000.

CHARLOT, Bernard. Da relação com o saber às práticas educativas. São Paulo: Cortez, 2013.

COUTO, Marcos A. C. Pensar por conceitos geográficos. In: CASTELAR, Sônia. (Org.). Educação geográfica: teorias e práticas docentes. São Paulo: Contexto, 2005. p. 79-96.

GAUTHIER, Clermont, et al. Por uma teoria da pedagogia: pesquisas contemporâneas sobre o saber docente. Trad. Francisco Pereira. Ijuí: Ed. UNIJUÍ, 1998.

KIMURA, Shoko. Geografia no ensino básico: questões e propostas. São Paulo: Contexto, 2008.

TARDIF, Maurice. Saberes docentes e formação profissional. 17. ed. Petrópolis: Vozes, 2014.

TARDIF, Maurice; LESSARD, Claude. O trabalho docente: elementos para uma teoria da docência como profissão de interações humanas. 8. ed. Trad. João B. Kreuch. Petrópolis: Vozes, 2013. 